\title{
Frequency of eating alone is associated with adolescent dietary intake, perceived food-related parenting practices and weight status: cross-sectional Family Life, Activity, Sun, Health, and Eating (FLASHE) Study results
}

\author{
Marla Reicks ${ }^{1, *}$, Cynthia Davey ${ }^{2}$, Alex Kojo Anderson $^{3}$, Jinan Banna ${ }^{4}$, Mary Cluskey ${ }^{5}$, \\ Carolyn Gunther ${ }^{6}$, Blake Jones ${ }^{7}$, Rickelle Richards ${ }^{8}$, Glade Topham ${ }^{9}$ and \\ Siew Sun Wong ${ }^{10}$ \\ 'Department of Food Science and Nutrition, University of Minnesota, 1334 Eckles Avenue, St. Paul, MN, 55108, \\ USA: ${ }^{2}$ Clinical and Translational Science Institute, University of Minnesota, Minneapolis, MN, USA: ${ }^{3}$ Foods and \\ Nutrition, University of Georgia, Athens, GA, USA: ${ }^{4}$ Department of Human Nutrition, Food and Animal Sciences, \\ University of Hawaii, Honolulu, HI, USA: ${ }^{5}$ School of Biological and Population Health Sciences, Oregon State \\ University, Corvallis, OR, USA: ${ }^{\circ}$ Department of Human Sciences, The Ohio State University, Columbus, OH, USA: \\ ${ }^{7}$ Psychology Department, Brigham Young University, Provo, UT, USA: ${ }^{8}$ Nutrition, Dietetics, and Food Science, \\ Brigham Young University, Provo, UT, USA: ${ }^{9}$ School of Family Studies and Human Services, Kansas State University, \\ Manhattan, KS, USA: ${ }^{1}$ Extension Family and Community Health Program, Oregon State University, Corvallis, OR, USA
}

Submitted 22 August 2018: Final revision received 1 December 2018: Accepted 3 January 2019: First published online 28 February 2019

\begin{abstract}
Objective: To examine relationships between frequency of adolescents eating alone (dependent variable) and diet, weight status and perceived food-related parenting practices (independent variables).

Design: Analyses of publicly available, cross-sectional, web-based survey data from adolescents.

Setting: Online consumer opinion panel.

Subjects: A US nationwide sample of adolescents (12-17 years) completed Family Life, Activity, Sun, Health, and Eating (FLASHE) Study surveys to report demographic and family meal characteristics, weight, dietary intake, home food availability and perceptions of parenting practices. Parents provided information about demographic characteristics. Logistic regression analyses were used to test for associations between variables.

Results: About $20 \%$ of adolescents reported often eating alone ( $n$ 343) $v$. not often eating alone ( $n$ 1309). Adjusted odds of adolescents often eating alone were significantly higher for non-Hispanic Black compared with non-Hispanic White adolescents $(\mathrm{OR}=1.7)$ and for overweight or obese compared with normal- or underweight adolescents $(\mathrm{OR}=1 \cdot 6)$. Adjusted odds of adolescents eating alone were significantly lower for those who reported that fruits and vegetables were often/always available in the home $(\mathrm{OR}=0.65)$, for those who perceived that parents had expectations about fruit and vegetable intake $(\mathrm{OR}=0.71)$ and for those who agreed with parental authority to make rules about intake of junk food/ sugary drinks $(\mathrm{OR}=0 \cdot 71)$. Junk food and sugary drink daily intake frequency was positively associated with often eating alone.

Conclusions: Often eating alone was related to being overweight/obese, having less healthy dietary intake and perceptions of less supportive food-related parenting practices.
\end{abstract}

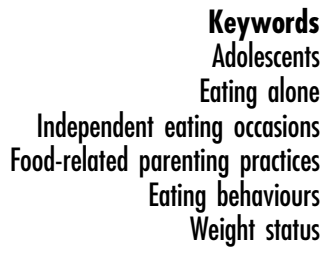

Keywords

Adolescents Eating alone Independent eating occasions Eating behaviours Weight status
Families play an important role in shaping health-related behaviours among adolescents, including dietary intake. Since the 1960s, the diversity in family living arrangements has increased with a decline in two-parent households and smaller families ${ }^{(1)}$. Further, traditional roles of family members have shifted. In 2014, labour force participation on the part of mothers of children younger than 18 years of age stood at $70 \%$, with three-quarters of all employed 
mothers working full-time ${ }^{(1)}$. Differences in family arrangements over the past 60 years have led to changes in the way in which food is consumed in the home. Previous research has reported differences in adolescents' meal patterns over time; for example, in a study of 14-15year-olds participating in the Growing up Today study, the number of family dinners per week decreased among both males and females from 1996 to $2008^{(2)}$. In the 2010 Project EAT (Eating and Activity in Teens) survey, decreases in family meal frequency were found from 1999 to 2010 among middle- and high-school students from low socioeconomic backgrounds ${ }^{(3)}$. These changes in family arrangements and meal patterns may collectively result in a greater number of independent eating occasions for adolescents or eating meals alone more often.

The trend for fewer family meals is significant given that adolescents whose families have less frequent meals together consume fewer fruits and vegetables (FV) and more sugar-sweetened beverages ${ }^{(4,5)}$. In addition, although findings are somewhat mixed ${ }^{(6)}$, research indicates that lower family meal frequency is related to higher odds of overweight and obesity for adolescents ${ }^{(7,8)}$ and 10 years later in young adults ${ }^{(9)}$. Mixed findings may be explained by the moderating effects of gender and race of the child, as well as by the influence of family routines and dynamics during mealtime. For instance, higher frequency of family meals has been associated with lower odds of overweight status for female, but not male adolescents ${ }^{(10,11)}$. Similarly, higher family meal frequency is related to lower risk of obesity among non-Hispanic White and non-Hispanic Black boys but higher risk among Hispanic boys ${ }^{(12)}$. In an observational study of family meals, Berge et $a l^{(7)}$ found that positive interpersonal dynamics during family meals, such as sharing emotional experiences, communicating interest in each other's lives and having clear expectations and rules, was predictive of higher vegetable intake and lower BMI among adolescents. These findings draw attention to the importance of developing a better understanding of the influences on adolescents' independent eating occasions, especially given that limited information is available regarding relationships of dietary quality, weight status and parenting practices with frequency of eating alone among adolescents $^{(13)}$.

Although little research has examined the parenting practices predictive of adolescents' healthy food choice during independent eating occasions ${ }^{(13)}$, it is likely that in this context, many of the parenting practices shown to be effective in non-independent eating occasions would remain important. These include modelling of healthy food choice ${ }^{(14)}$, avoidance of restriction or pressure ${ }^{(15)}$, supportive monitoring of eating behaviours ${ }^{(16)}$ and making healthy foods available ${ }^{(17)}$. Of particular interest in relation to adolescents' independent eating occasions are parenting practices that foster autonomous or intrinsic motivation in youth, such that youth will desire to engage in positive behaviours even when parents are not around.
Autonomy-supportive parenting includes providing a clear rationale for the desired behaviour, providing choice, and avoiding using pressured or coercive language ${ }^{(18)}$. Autonomy-supportive parenting has been shown to lead to increased intrinsic motivation, greater receptivity to parent influence and positive outcomes in youth ${ }^{(19)}$. Autonomous or intrinsic motivation may be particularly important in predicting adolescents' healthy food choice in independent eating occasions. Higher autonomous motivation (based on a two-item self-report measure) was related to increased frequency of $\mathrm{FV}$ intake (these findings were observed in the same nationwide sample of adolescents as in the current study based on data collected for the Family, Life, Activity, Sun, Health and Eating (FLASHE) Study) ${ }^{(20)}$. In a study utilizing a two-wave prospective survey design, high-school students self-reported perceptions of autonomy support, autonomous motivation and behaviour via questionnaires ${ }^{(21)}$. Autonomy-supportive parenting predicted autonomous motivation, which in turn predicted perceived behavioural control (confidence in eating at least five portions of FV each day), which predicted increased FV consumption ${ }^{(21)}$.

Studies are limited regarding the relationships between adolescent independent eating occasions or eating alone and dietary intake, and adolescent perceptions of supportive food-related parenting practices such as making healthy foods available, modelling intake of healthy foods and setting expectations for eating healthy foods. Adolescent perceptions of food-related parenting practices reflect how the adolescent experiences his/her home food environment from a physical and social perspective in a way that is relevant to his/her behaviour. Other studies have previously examined relationships between adolescent perceptions of food-related parenting practices and adolescent dietary intake ${ }^{(21-23)}$. The purpose of the current cross-sectional survey study based on analysis of secondary data from a nationwide sample of adolescents was to test hypotheses that the frequency of eating alone (dependent variable) was associated with dietary behaviours, weight status and perceived food-related parenting practices that support healthy eating (independent variables).

\section{Methods}

\section{Study overview}

The present study used publicly available, existing data collected from adolescents (aged 12-17 years) participating in the cross-sectional FLASHE Study ${ }^{(24)}$ regarding demographic characteristics, weight, home food availability, evening meal types, food-related parenting practices and dietary intake. Data collected from the adolescents' parents regarding parent demographic and household characteristics were also used to assess relationships with the frequency of adolescents eating alone. 
The FLASHE Study was sponsored by the US National Cancer Institute to determine how lifestyle behaviours such as diet and physical activity are related to cancer risk. Data were collected under a contract with Westat, Inc. using web-based surveys from participants recruited and enrolled via the Ipsos' Consumer Opinion Internet Panel from April to October 2014. A total of 5027 parent and adolescent dyads were screened and 1945 were enrolled in the study with an overall response rate of $29.4 \%$. All study procedures were completed by 1479 dyads. Details on the design, sampling, recruitment, enrolment and participant characteristics have been reported previously 25,26$)$ and are available from the FLASHE Study website ${ }^{(24,27)}$. A non-probability sample was obtained from the Ipsos survey panel company to be representative of the US general population regarding sex, education, income, age and Census region. Adult panel members were screened for eligibility regarding whether they were the parent of an eligible adolescent and lived with the adolescent half of the time or more. One eligible adolescent was selected until quotas for three age ranges were filled. About one-third of adolescent participants were recruited in each age range with one-half boys and onehalf girls. Dyads were invited to complete diet and physical activity surveys.

Because the FLASHE data are a quota sample from a consumer panel, survey weights were created as 'analysis weights' to make the weighted sample more similar to the general population. Survey weights were constructed through raking procedures on key sociodemographic variables as an attempt to reduce potential bias from population values ${ }^{(26)}$. The four raking variables used to construct weights for adolescents who completed the diet survey were age, gender, race/ethnicity and Census region (Northeast, Midwest, South, West). According to the limitations described, statistical inference for variables other than these four raking variables are subject to selection bias; therefore, results of unadjusted associations and adjusted models cannot be generalized to the US general adolescent population.

Data for the current individual-level analysis were downloaded from the FLASHE Study website ${ }^{(24)}$ and included data collected via the Adolescent Demographic Survey instrument, the Adolescent Diet Survey instrument and the Parent Demographic Survey instrument. The University of Minnesota's Institutional Review Board determined that this secondary analysis of existing anonymous data was exempt from review.

\section{Measures}

Adolescent demographic and physical characteristics Adolescents reported their age, sex, race/ethnicity and height and weight. BMI percentiles were calculated according to Centers for Disease Control and Prevention guidelines ${ }^{(28)}$ by the FLASHE Study programme investigators and used to classify adolescents as follows: underweight (BMI $<5$ th percentile), normal weight (BMI 5 th $-<85$ th percentile), overweight (BMI 85th- $<95$ th percentile) and obese (BMI $\geq 95$ th percentile). Adolescent BMI percentile variables were included in the publicly available FLASHE data $^{(24)}$.

\section{Food availability}

Adolescents' perceptions of food availability in the home were assessed with a series of questions ('How often are the following foods and drinks available in your home? fruits or vegetables, sweets, sugary drinks and chips'). Response options were on a 5-point scale from 'never' to 'always' and collapsed into binary variables for analysis (often/always $v$. sometimes/rarely/never).

\section{Food-related parenting practices}

Adolescents reported perceptions of parenting practices by rating their agreement with a series of six statements regarding what parent(s) say and do when it comes to eating FV and a series of six statements regarding what parent(s) say and do when it comes to eating junk food/ drinking sugary drinks ${ }^{(29-31)}$. Food-related parenting practices addressed management of availability, role modelling and setting expectations for FV and junk food/ sugary beverages. Statements regarding FV included: 'My parent(s) buy fruits and vegetables for me'; 'My parent(s) try to eat fruits and vegetables when I'm around'; 'My parent(s) encourage me to try different kinds of fruits and vegetables'; 'My parent(s) and I decide together how many fruits and vegetables I have to eat'; 'My parent(s) have to make sure that I eat enough fruits and vegetables'; and 'My parent(s) make me eat fruits and vegetables'. Statements regarding junk food/sugary drinks included: 'If I've had a bad day, my parent(s) let me have junk food or sugary drinks to make me feel better'; 'My parent(s) don't buy a lot of junk food or sugary drinks for me'; 'My parent(s) try to avoid eating junk food or sugary drinks when I'm around'; 'My parent(s) and I decide together how much junk food or sugary drinks I can have'; 'My parent(s) have to make sure that I don't eat too much junk food or drink too many sugary drinks'; and 'My parent(s) decide how much junk food or sugary drinks I can have'. Another statement was included in each series to assess adolescents' beliefs about the acceptability and authority parents have when making rules about intake ${ }^{(32)}$ : 'It's OK for my parent(s) to make rules about how many fruits and vegetables I can have'; and 'It's OK for my parent(s) to make rules about how much junk food or sugary drinks I can have'. Response options were on a 5-point Likert-type scale from 'strongly disagree' to 'strongly agree' collapsed into binary variables for analysis (somewhat agree/ strongly agree $v$. neither agree nor disagree/somewhat disagree/strongly disagree). Junk food was defined in the FLASHE users' guide as a category that included candy/ chocolate, cookies/cake, potato chips, fried potatoes and 
frozen desserts ${ }^{(27)}$. Fried potatoes were defined for adolescents as 'fried potatoes like French fries, tater tots, hash brown potatoes, etc.'.

\section{Evening meal types}

Adolescents were asked to characterize the types of evening meals eaten at home. Evening meal types eaten at home were described as foods: (i) purchased from a fast-food restaurant and eaten at home; (ii) delivered to your home like pizza or Chinese food; (iii) made from a heat-and-serve or box meal like Spaghetti-Os ${ }^{\circledR}$, a microwave meal or frozen pizza and eaten at home; and (iv) cooked from scratch or a recipe and eaten at home. Responses were 0-7 representing the number of days in the past week that the evening meal was comprised of each type of foods. Mean values are the average number of days in the past week for each type of evening meal eaten at home.

\section{Daily food frequency}

Adolescents were asked how many times they consumed foods and beverages during the past $7 \mathrm{~d}$, with responses from 1 to 6: $1=$ 'I did not (eat or drink this food or beverage) in the past 7 days'; $2=$ ' $1-3$ times in the past 7 days'; $3=$ ' $4-6$ times in the past 7 days'; $4=$ ' 1 time per day'; $5=$ '2 times per day'; and $6=3$ or more times per day'. Mean daily intake food frequency scores were calculated as the average number of times per day that foods in several indicated food groups were eaten. Before combining food items into the daily food frequency scales, each item response was converted to a daily frequency ${ }^{(27)}$ : 'never' $=0 ; 1-3$ times in past 7 days' $=0 \cdot 29$; ' $4-6$ times in past 7 days' $=0.71$; ' 1 time per day' $=1$; '2 times per day' $=2$; and ' 3 or more times per day' $=3$. The items included in each daily intake food frequency scale are defined in the FLASHE users' guide ${ }^{\text {(27) }}$. Junk food included the sum of daily intake food frequencies for candy/chocolate, cookies/cake, potato chips, fried potatoes and frozen desserts. Convenience/fast food included the sum of daily intake food frequencies for fried potatoes, fried chicken, pizza, tacos, burgers and heat-and-serve foods. Sugar-sweetened beverages included the sum of daily intake food frequencies for soda, energy drinks, sweetened fruit drinks and sports drinks. Sugary foods included the sum of daily intake food frequencies for frozen desserts, cookies/cake, candy/chocolate and sugary cereal. Fatty meats included fried chicken, burgers and processed meat. All detrimental foods included the sum of daily intake food frequencies for junk food, convenience/ fast food, sugary foods, fatty meat and sugar-sweetened beverages. FV included the sum of daily intake food frequencies for $100 \%$ fruit juice, fruit, green salad, other nonfried vegetables, cooked beans and other potatoes. Other potatoes were defined for adolescents as 'any other kind of potatoes that aren't fried like baked, boiled, mashed or potatoes used in soups and stews'. All beneficial foods included the sum of daily intake food frequencies for $\mathrm{FV}$, water, wholegrain bread, cooked whole grains and nonsugary cereal. Those with missing data for any item within a food group did not receive a score for that food group. As a result, daily intake food frequency scale scores were missing for sixty to 203 adolescents, depending on the scale.

To deal with potential overestimation, daily intake frequencies for each food group were top-coded by the FLASHE Study programme investigators and included in the publicly available data ${ }^{(24)}$. A top-code or upper limit was set for daily intake frequency values based on consideration of possible overestimations of intake by adolescents. Values were considered overestimates if reported intakes corresponded to $Z$-scores $\geq|3 \cdot 29|$ (i.e. where $99.95 \%$ of scores would fall in a normal distribution). If the reported value corresponded with a $Z$-score $\geq 13 \cdot 29 \mid$, it was replaced with the value nearest to it without having a $Z$ score $\geq|3 \cdot 29|^{(27)}$.

\section{Dependent variable: eating alone}

Adolescents rated their agreement with the statement 'In my family, I often eat alone' on a 5-point Likert-type scale from 'strongly disagree' to 'strongly agree'. Responses were combined to create a binary eating alone variable for analysis. The 'often eat alone' group included 'strongly agree' and 'somewhat agree' responses. The 'does not often eat alone' group included 'strongly disagree', 'somewhat disagree' and 'neither disagree nor agree' responses.

\section{Parent demographic and bousebold characteristics}

Parents reported their highest grade or level of education completed, age, sex, employment status, hours worked per week if applicable, marital status and annual household income. Household income responses were collected for five income categories, recoded into two categories by the FLASHE Study programme investigators and included in the publicly available data $(<\$$ US10000 and $\geq \$$ US $100000)^{(24)}$.

\section{Statistical methods}

The $\chi^{2}$ test was used to test for associations of adolescent demographic and weight status variables, parent demographic and household characteristics, food availability measures and perceptions of parenting practices regarding FV and junk food or sugary drinks with the binary variable for eating alone. The two-sample $t$ test was used to test for associations between eating alone and days for evening meal types. Food intake frequency scores were not normally distributed, therefore the non-parametric Wilcoxon rank-sum test was used to test for differences in distribution of food intake frequency scores by eating alone status.

Stepwise selection logistic regression models were run including adolescent and parent demographic characteristics, weight status, perceived food-related parenting 
practice variables, food availability and food frequency variables with the raked weight variable for the Adolescent Diet Survey ${ }^{(27)}$. Assumptions of logistic regression were met which included use of a dichotomous dependent outcome variable (eating alone status) and no multicollinearity observed among independent variables. All correlations between independent variables included in models were $<0.90$ except for fast foods and fast foods with no frozen desserts $(r=0 \cdot 96)$. OR estimates from the regression models are the odds of adolescents somewhat/ strongly agreeing that they often eat alone for the indicated group $v$. the reference group.

The significance level was set at 0.05 for all statistical tests and models, and was adjusted using the Bonferroni correction for multiple comparisons. The statistical software package SAS version 9.4 (C) 2002-2012) was used to conduct the analyses.

\section{Results}

The study sample consisted of 1652 adolescents who answered the question about eating alone. Of these, 343 (21\%) somewhat or strongly agreed that they often eat alone ('often eat alone' group) and 1309 (79\%) strongly/ somewhat disagreed/neither disagreed nor agreed that they often eat alone ('does not often eat alone' group; Table 1). Two-thirds of all adolescents (67\%) were 14-17 years of age; about half were male $(50 \%)$. The majority were non-Hispanic White (64\%) and normal weight (68\%). The majority of parents reported having some college education or a 4 -year degree or higher $(82 \%)$ and had a household income <\$US 100000 (79\%). The majority of parents were female $(74 \%)$, employed for wages (58\%) and married (72\%). Based on unadjusted analyses using $\chi^{2}$ tests, adolescents in the 'often eat alone' group were more likely to be non-Hispanic Black (24 $v$. $15 \%)$, overweight or obese (37 v. 26\%) and less likely to have parents who were married (67v. 74\%) compared with the 'does not often eat alone' group.

Table 2 shows results of unadjusted analyses based on $\chi^{2}$ tests regarding responses to questions about home availability of foods and beverages. Adolescents who reported that they often eat alone were significantly less likely to have $\mathrm{FV}$ often to always available ( $72 v .84 \%$, $P<0.0001)$ than adolescents who did not often eat alone (Table 2). Availability of sugary drinks, sweets and chips was not associated with often eating alone or not often eating alone.

For all food-related parenting practices regarding FV, adolescents in the 'often eat alone' group were significantly less likely to agree with each parenting practice statement than adolescents in the 'does not often eat alone' group (Table 3) based on unadjusted analyses using $\chi^{2}$ tests. Adolescents reporting they often eat alone were significantly more likely to agree that parents let them have junk food or sugary drinks if they had a bad day (27 v. 17\%) and were less likely to agree that parents don't buy a lot of junk food or sugary drinks ( $44 v .53 \%$ ) and that it's OK for parents to make rules about junk food or sugary drinks ( $48 v .59 \%$ ) than adolescents reporting they did not often eat alone (Table 4).

The mean number of days (over the past $7 \mathrm{~d}$ ) for each evening meal type (purchased from a fast-food restaurant, delivered, made from a heat-and-serve or box meal, and cooked from scratch or a recipe) differed by eating alone group based on unadjusted analyses using two-sample $t$ tests where $P<0.0125$ was significant after adjusting for multiple comparisons. Adolescents in the 'often eat alone' group had a significantly higher mean number of days (1.18 (SD 1.43), 0.55 (SD 1.11) and 1.43 (SD 1.69)) with an evening meal purchased from a fast-food restaurant and eaten at home $(P<0.0001)$, delivered to their home $(P=0.010)$ and made from a heat-and-serve or box meal and eaten at home $(P<0.0001)$, respectively, than those in the 'does not often eat alone' group (0.72 (sD 0.98), 0.38 (SD 0.71) and 0.88 (sD 1.22), respectively). Consistent with higher mean number of days for these three evening meal types, adolescents in the 'often eat alone' group had significantly fewer mean number of days with an evening meal cooked from scratch or a recipe and eaten at home (3.41 (sD 2.40)) than those in the 'does not often eat alone' group (4.29 (SD 2.10); $P<0.0001$ ).

Unadjusted analysis using Wilcoxon signed-rank tests showed that adolescents who reported that they often eat alone had significantly higher median daily intake frequency of convenience/fast food and fatty meats than those who reported that they do not often eat alone (Table 5). Adolescents who reported that they often eat alone also had significantly lower median daily intake frequency of all beneficial foods and FV than adolescents who did not report often eating alone (Table 5).

The final logistic regression model included adolescent age, race/ethnicity, sex, binary weight status, FV availability, sweets availability, two perceived food-related parenting practice items ('My parent(s) and I decide together how many fruits and vegetables I have to eat' and 'It's OK for parent(s) to make rules about junk food'), FV daily intake frequency, junk food/sugary drinks without frozen desserts or energy drinks daily intake frequency and a parent demographic variable (marital status). In the weighted logistic regression model adjusted for other factors (Table 6), the odds of adolescents somewhat/ strongly agreeing that they often eat alone were significantly higher for non-Hispanic Black adolescents compared with non-Hispanic White adolescents (OR= 1.7), for adolescents with overweight or obese weight status compared with normal- or underweight status $(\mathrm{OR}=1 \cdot 6)$, for adolescents who reported that sweets were often/always available in the home $(\mathrm{OR}=1.4)$ and for each one additional daily intake frequency of junk food/ sugary drinks $(\mathrm{OR}=1 \cdot 1)$. However, the adjusted odds of adolescents often eating alone were not significantly 
Table 1 Unadjusted associations between eating alone and demographic and physical characteristics among US adolescents (aged 12-17 years) who completed Family Life, Activity, Sun, Health, and Eating (FLASHE) Study surveys, April-October 2014

\begin{tabular}{|c|c|c|c|c|c|c|c|}
\hline \multirow[b]{3}{*}{ Demographic and weight characteristics } & & & \multicolumn{4}{|c|}{ Eating alone group* } & \multirow[b]{3}{*}{$P$ value- } \\
\hline & \multicolumn{2}{|c|}{$\begin{array}{c}\text { All } \\
(n 1652)\end{array}$} & \multicolumn{2}{|c|}{$\begin{array}{l}\text { Often eat alone } \\
\qquad(n 343)\end{array}$} & \multicolumn{2}{|c|}{$\begin{array}{l}\text { Does not often eat alone } \\
\qquad(n \text { 1309) }\end{array}$} & \\
\hline & $n \dagger$ & $\% \dagger$ & $n \dagger$ & $\% \dagger$ & $n \dagger$ & $\% \dagger$ & \\
\hline \multicolumn{8}{|l|}{ Adolescent age group ( $n$ 1632) } \\
\hline $12-13$ years & 545 & 33.4 & 92 & $27 \cdot 3$ & 453 & $35 \cdot 0$ & \\
\hline $14-17$ years & 1087 & $66 \cdot 6$ & 245 & 72.7 & 842 & 65.0 & 0.008 \\
\hline \multicolumn{8}{|l|}{ Adolescent sex ( $n$ 1628) } \\
\hline Male & 807 & $49 \cdot 6$ & 161 & $47 \cdot 9$ & 646 & $50 \cdot 0$ & \\
\hline Female & 821 & $50 \cdot 4$ & 175 & $52 \cdot 1$ & 646 & $50 \cdot 0$ & 0.496 \\
\hline \multicolumn{8}{|l|}{ Adolescent race/ethnicity ( $n$ 1616) } \\
\hline Hispanic & 160 & 9.9 & 31 & $9 \cdot 3$ & 129 & $10 \cdot 1$ & \\
\hline Non-Hispanic Black alone & 271 & $16 \cdot 8$ & 81 & $24 \cdot 2$ & 190 & $14 \cdot 8$ & \\
\hline Non-Hispanic White alone & 1033 & 63.9 & 188 & $56 \cdot 1$ & 845 & $66 \cdot 0$ & \\
\hline Other & 152 & 9.4 & 35 & $10 \cdot 4$ & 117 & $9 \cdot 1$ & 0.0003 \\
\hline \multicolumn{8}{|l|}{ Adolescent weight status ( $n$ 1592) } \\
\hline Underweight (BMI $<5$ th percentile) & 66 & 4.2 & 6 & 1.8 & 60 & 4.8 & \\
\hline Normal weight (BMI 5th $-<85$ th percentile) & 1080 & 67.8 & 201 & $61 \cdot 1$ & 879 & $69 \cdot 6$ & \\
\hline Overweight (BMI 85th $-<95$ th percentile) & 245 & $15 \cdot 4$ & 68 & 20.7 & 177 & $14 \cdot 0$ & \\
\hline Obese (BMI $\geq 95$ th percentile) & 201 & $12 \cdot 6$ & 54 & $16 \cdot 4$ & 147) & 11.6 & 0.0001 \\
\hline \multicolumn{8}{|l|}{ Parent education ( $n$ 1632) } \\
\hline High school/General Equivalency Diploma or less & 293 & 17.9 & 61 & $18 \cdot 1$ & 232 & 17.9 & \\
\hline Some college or more & 1339 & $82 \cdot 1$ & 276 & 81.9 & 1063 & $82 \cdot 1$ & 0.937 \\
\hline \multicolumn{8}{|l|}{ Household income ( $n$ 1619) } \\
\hline$<\$$ US 100000 & 1284 & $79 \cdot 3$ & 274 & $81 \cdot 8$ & 1010 & 78.7 & \\
\hline$\geq \$$ US 100000 & 335 & $20 \cdot 7$ & 61 & $18 \cdot 2$ & 274 & 21.3 & 0.208 \\
\hline \multicolumn{8}{|l|}{ Parent age group ( $n$ 1637) } \\
\hline 18-34 years & 188 & 11.5 & 35 & $10 \cdot 3$ & 153 & $11 \cdot 8$ & \\
\hline $35-44$ years & 710 & 43.4 & 140 & $41 \cdot 3$ & 570 & 43.9 & \\
\hline $45-59$ years & 692 & $42 \cdot 3$ & 157 & $46 \cdot 3$ & 535 & 41.2 & \\
\hline$\geq 60$ years & 47 & 2.9 & 7 & $2 \cdot 1$ & 40 & 3.1 & 0.315 \\
\hline \multicolumn{8}{|l|}{ Parent sex ( $n$ 1637) } \\
\hline Male & 421 & $25 \cdot 7$ & 82 & $24 \cdot 3$ & 339 & $26 \cdot 1$ & \\
\hline Female & 1216 & $74 \cdot 3$ & 256 & $75 \cdot 7$ & 960 & 73.9 & 0.491 \\
\hline \multicolumn{8}{|l|}{ Parent employment status ( $n$ 1630) } \\
\hline Employed for wages & 937 & 57.5 & 205 & $60 \cdot 8$ & 732 & $56 \cdot 6$ & \\
\hline Self-employed or not employed§ & 693 & $42 \cdot 5$ & 132 & 39.2 & 561 & 43.4 & 0.163 \\
\hline \multicolumn{8}{|l|}{ Parent hours worked/week $\|(n$ 1067) } \\
\hline $0-14 \mathrm{~h}$ & 59 & 5.5 & 14 & $6 \cdot 1$ & 45 & 5.4 & \\
\hline $15-30 \mathrm{~h}$ & 197 & 18.5 & 50 & 21.7 & 147 & $17 \cdot 6$ & \\
\hline $31-40 \mathrm{~h}$ & 513 & $48 \cdot 1$ & 115 & $49 \cdot 8$ & 398 & $47 \cdot 6$ & \\
\hline$\geq 41 \mathrm{~h}$ & 298 & $27 \cdot 9$ & 52 & 22.5 & 246 & 29.4 & 0.169 \\
\hline \multicolumn{8}{|l|}{ Parent marital status ( $n$ 1619) } \\
\hline Married & 1175 & $72 \cdot 4$ & 224 & $66 \cdot 7$ & 951 & 73.9 & \\
\hline Divorced, widowed, separated & 200 & $12 \cdot 3$ & 54 & $16 \cdot 1$ & 146 & $11 \cdot 3$ & \\
\hline Never married & 157 & $9 \cdot 7$ & 42 & $12 \cdot 5$ & 115 & 8.9 & \\
\hline Member of unmarried couple & 91 & $5 \cdot 6$ & 16 & 4.8 & 75 & $5 \cdot 8$ & 0.013 \\
\hline
\end{tabular}

*Responses to the statement 'In my family, I often eat alone' were used to identify eating alone groups: 'does not often eat alone' group = 'strongly disagree', 'somewhat disagree' and 'neither disagree nor agree' responses; 'often eat alone' group = 'strongly agree' and 'somewhat agree' responses.

$\dagger n$ and \% of total with non-missing data.

$\ddagger P$ value for $X^{2}$ test; $P<0.008$ is significant after adjusting for multiple comparisons (Bonferroni correction).

$\S$ Not employed includes out of work, homemaker, student and retired.

॥Work hours not available if parent was not employed for wages or self-employed.

different by adolescent age group or parent marital status. Adjusted odds of adolescents often eating alone were significantly lower for adolescents who reported that FV were often/always available in the home $(\mathrm{OR}=0.65)$, for adolescents who agreed that they made decisions with parents about how many FV they have to eat $(\mathrm{OR}=0.71)$ and for adolescents who agreed that it's OK for parents to make rules about how much junk food/sugary drinks they can have $(\mathrm{OR}=0.71)$.

\section{Discussion}

Although research has examined the influence of eating shared family meals on adolescents' risk for overweight or obesity and eating patterns, less is known about the influence of adolescents' independent eating occasions on their weight status and eating patterns ${ }^{(13)}$. The adolescent life stage is particularly important to examine in relation to independent eating occasions because during these years 
Table 2 Unadjusted associations between eating alone and perceptions of home food availability among US adolescents (aged 12-17 years) who completed Family Life, Activity, Sun, Health, and Eating (FLASHE) Study surveys, April-October 2014

\begin{tabular}{|c|c|c|c|c|c|c|c|}
\hline \multirow{3}{*}{$\begin{array}{l}\text { Food availability (How often are these } \\
\text { foods available in your home?) }\end{array}$} & & & \multicolumn{4}{|c|}{ Eating alone group* } & \multirow[b]{3}{*}{$P$ value $\neq$} \\
\hline & \multicolumn{2}{|c|}{$\begin{array}{c}\text { All } \\
\text { (n 1652) }\end{array}$} & \multicolumn{2}{|c|}{$\begin{array}{l}\text { Often eat alone } \\
\qquad(n \text { 343) }\end{array}$} & \multicolumn{2}{|c|}{$\begin{array}{l}\text { Does not often eat alone } \\
\qquad(n \text { 1309) }\end{array}$} & \\
\hline & $n \dagger$ & $\% †$ & $n \dagger$ & $\% \dagger$ & $n \dagger$ & $\% \dagger$ & \\
\hline \multicolumn{8}{|l|}{ Fruits or vegetables ( $n$ 1645) } \\
\hline Never/rarely/sometimes & 309 & $18 \cdot 8$ & 94 & $27 \cdot 8$ & 215 & $16 \cdot 4$ & \\
\hline Often/always & 1336 & $81 \cdot 2$ & 244 & $72 \cdot 2$ & 1092 & $83 \cdot 6$ & $<0.0001$ \\
\hline \multicolumn{8}{|l|}{ Sweets§ $(n 1651)$} \\
\hline Never/rarely/sometimes & 907 & 54.9 & 169 & $49 \cdot 3$ & 738 & $56 \cdot 4$ & \\
\hline Often/always & 744 & $45 \cdot 1$ & 174 & $50 \cdot 7$ & 570 & $43 \cdot 6$ & 0.018 \\
\hline \multicolumn{8}{|l|}{ Sugary drinks $\|(n$ 1645) } \\
\hline Never/rarely/sometimes & 916 & $55 \cdot 7$ & 174 & $51 \cdot 2$ & 742 & $56 \cdot 9$ & \\
\hline Often/always & 729 & $44 \cdot 3$ & 166 & $48 \cdot 8$ & 563 & $43 \cdot 1$ & 0.060 \\
\hline \multicolumn{8}{|l|}{ Chipsף $(n 1650)$} \\
\hline Never/rarely/sometimes & 863 & $52 \cdot 3$ & 172 & $50 \cdot 3$ & 691 & $52 \cdot 8$ & \\
\hline Often/always & 787 & $47 \cdot 7$ & 170 & $49 \cdot 7$ & 617 & $47 \cdot 2$ & 0.403 \\
\hline
\end{tabular}

*Responses to the statement 'In my family, I often eat alone' were used to identify eating alone groups: 'does not often eat alone' group = 'strongly disagree', 'somewhat disagree' and 'neither disagree nor agree' responses; 'often eat alone' group = 'strongly agree' and 'somewhat agree' responses.

t $n$ and $\%$ of total with non-missing data.

$\ddagger P$ value for $X^{2}$ test; $P<0.0125$ is significant after adjusting for multiple comparisons (Bonferroni correction).

$\S$ Candy, cookies, cake, ice cream, etc.

||Regular soda, sports drinks, fruit drinks, sweetened teas and other drinks with added sugar.

IRegular potato chips, corn chips or cheese puffs like Lays, Doritos, Cheetos, etc.

Table 3 Unadjusted associations between eating alone and parenting practices regarding fruits and vegetables (FV) among US adolescents (aged 12-17 years) who completed Family Life, Activity, Sun, Health, and Eating (FLASHE) Study surveys, April-October 2014

\begin{tabular}{|c|c|c|c|c|c|c|c|}
\hline \multirow[b]{3}{*}{ Agreement with statements* } & \multirow{2}{*}{\multicolumn{2}{|c|}{$\begin{array}{c}\text { All } \\
(n 1652)\end{array}$}} & \multicolumn{4}{|c|}{ Eating alone group $\dagger$} & \multirow[b]{3}{*}{$P$ value§ } \\
\hline & & & \multicolumn{2}{|c|}{$\begin{array}{l}\text { Often eat alone } \\
\qquad(n 343)\end{array}$} & \multicolumn{2}{|c|}{$\begin{array}{l}\text { Does not often eat alone } \\
\qquad(n \text { 1309) }\end{array}$} & \\
\hline & $n \ddagger$ & $\% \ddagger$ & $n \ddagger$ & $\% \ddagger$ & $n \ddagger$ & $\% \ddagger$ & \\
\hline \multicolumn{8}{|l|}{ My parent(s) buy FV for me ( $n$ 1648) } \\
\hline Disagree/neither agree nor disagree & 165 & $10 \cdot 0$ & 56 & $16 \cdot 4$ & 109 & 8.3 & \\
\hline Agree & 1483 & $90 \cdot 0$ & 285 & 83.6 & 1198 & 91.7 & $<0.0001$ \\
\hline \multicolumn{8}{|c|}{ My parent(s) try to eat FV when I'm around ( $n$ 1645) } \\
\hline Disagree/neither agree nor disagree & 400 & $24 \cdot 3$ & 107 & 31.4 & 293 & 22.5 & \\
\hline Agree & 1245 & $75 \cdot 7$ & 234 & 68.6 & 1011 & 77.5 & 0.0006 \\
\hline \multicolumn{8}{|c|}{ My parent(s) encourage me to try different kinds of FV ( $n$ 1638) } \\
\hline Disagree/neither agree nor disagree & 224 & $13 \cdot 7$ & 72 & $21 \cdot 3$ & 152 & 11.7 & \\
\hline Agree & 1414 & $86 \cdot 3$ & 266 & 78.7 & 1148 & 88.3 & $<0.0001$ \\
\hline \multicolumn{8}{|c|}{ My parent(s) and I decide together how many FV I have to eat ( $n$ 1640) } \\
\hline Disagree/neither agree nor disagree & 960 & 58.5 & 225 & 66.4 & 735 & $56 \cdot 5$ & \\
\hline Agree & 680 & 41.5 & 114 & 33.6 & 566 & 43.5 & 0.001 \\
\hline \multicolumn{8}{|c|}{ My parent(s) have to make sure that I eat enough FV ( $n 1640)$} \\
\hline Disagree/neither agree nor disagree & 731 & 44.6 & 180 & 52.9 & 551 & $42 \cdot 4$ & \\
\hline Agree & 909 & $55 \cdot 4$ & 160 & $47 \cdot 1$ & 749 & 57.6 & 0.0005 \\
\hline \multicolumn{8}{|c|}{ My parent(s) make me eat FV ( $n$ 1640) } \\
\hline Disagree/neither agree nor disagree & 761 & $46 \cdot 4$ & 190 & $55 \cdot 9$ & 571 & $43 \cdot 9$ & \\
\hline Agree & 879 & $53 \cdot 6$ & 150 & $44 \cdot 1$ & 729 & $56 \cdot 1$ & $<0.0001$ \\
\hline \multicolumn{8}{|c|}{ It's OK for my parent(s) to make rules about how many FV I can have ( $n$ 1644) } \\
\hline Disagree/neither agree nor disagree & 739 & $45 \cdot 0$ & 177 & 51.9 & 562 & 43.1 & \\
\hline Agree & 905 & 55.0 & 164 & $48 \cdot 1$ & 741 & $56 \cdot 9$ & 0.004 \\
\hline
\end{tabular}


Table 4 Unadjusted associations between eating alone and parenting practices regarding junk food (JF) and sugary drinks among US adolescents (aged 12-17 years) who completed Family Life, Activity, Sun, Health, and Eating (FLASHE) Study surveys, April-October 2014

\begin{tabular}{|c|c|c|c|c|c|c|c|}
\hline \multirow[b]{3}{*}{ Agreement with statements* } & \multirow{2}{*}{\multicolumn{2}{|c|}{$\begin{array}{c}\text { All } \\
(n \text { 1652) }\end{array}$}} & \multicolumn{4}{|c|}{ Eating alone group $\dagger$} & \multirow[b]{3}{*}{$P$ value§ } \\
\hline & & & \multicolumn{2}{|c|}{$\begin{array}{l}\text { Often eat alone } \\
\qquad(n \text { 343) }\end{array}$} & \multicolumn{2}{|c|}{$\begin{array}{l}\text { Does not often eat alone } \\
\qquad(n \text { 1309) }\end{array}$} & \\
\hline & $n \ddagger$ & $\% \ddagger$ & $n \ddagger$ & $\% \ddagger$ & $n \ddagger$ & $\% \ddagger$ & \\
\hline \multicolumn{8}{|c|}{ If l've had a bad day, my parent(s) let me have JF or sugary drinks to make me feel better ( $n$ 1649) } \\
\hline Disagree/neither agree nor disagree & 1331 & 80.7 & 249 & 73.0 & 1082 & $82 \cdot 7$ & \\
\hline Agree & 318 & $19 \cdot 3$ & 92 & $27 \cdot 0$ & 226 & $17 \cdot 3$ & $<0.0001$ \\
\hline \multicolumn{8}{|c|}{ My parent(s) don't buy a lot of JF or sugary drinks for me ( $n$ 1648) } \\
\hline Disagree/neither agree nor disagree & 805 & 48.9 & 190 & 55.9 & 615 & $47 \cdot 0$ & \\
\hline Agree & 843 & $51 \cdot 2$ & 150 & $44 \cdot 1$ & 693 & 53.0 & 0.004 \\
\hline \multicolumn{8}{|c|}{ My parent(s) try to avoid eating JF or sugary drinks when I'm around $(n 1642)$} \\
\hline Disagree/neither agree nor disagree & 981 & $59 \cdot 7$ & 219 & 64.6 & 762 & 58.5 & \\
\hline Agree & 661 & $40 \cdot 3$ & 120 & 35.4 & 541 & 41.5 & 0.041 \\
\hline \multicolumn{8}{|c|}{ My parent(s) and I decide together how much JF or sugary drinks I can have ( $n$ 1647) } \\
\hline Disagree/neither agree nor disagree & 979 & $59 \cdot 4$ & 210 & $62 \cdot 0$ & 769 & $58 \cdot 8$ & \\
\hline Agree & 668 & $40 \cdot 6$ & 129 & 38.0 & 539 & $41 \cdot 2$ & 0.292 \\
\hline \multicolumn{8}{|c|}{ My parent(s) have to make sure that I don't eat too much JF or drink too many sugary drinks $(n 1646)$} \\
\hline Disagree/neither agree nor disagree & 848 & 51.5 & 183 & 54.0 & 665 & $50 \cdot 9$ & \\
\hline Agree & 798 & $48 \cdot .5$ & 156 & $46 \cdot 0$ & 642 & $49 \cdot 1$ & 0.308 \\
\hline \multicolumn{8}{|c|}{ My parent(s) decide how much JF or sugary drinks I can have ( $n$ 1648) } \\
\hline Disagree/neither agree nor disagree & 899 & $54 \cdot 6$ & 202 & $59 \cdot 2$ & 697 & $53 \cdot 3$ & \\
\hline Agree & 749 & $45 \cdot 4$ & 139 & $40 \cdot 8$ & 610 & $46 \cdot 7$ & 0.051 \\
\hline \multicolumn{8}{|c|}{ It's OK for parent(s) to make rules about how much JF or sugary drinks I can have ( $n$ 1645) } \\
\hline Disagree/neither agree nor disagree & 713) & $43 \cdot 3$ & 176 & 51.6 & 537 & $41 \cdot 2$ & \\
\hline Agree & 932 & $56 \cdot 7$ & 165 & 48.4 & 767 & $58 \cdot 8$ & 0.0005 \\
\hline
\end{tabular}

*Adolescents responded to the following question for each statement: 'How much do you disagree or agree with statements regarding what your parent(s) say and do when it comes to eating junk food or drinking sugary drinks?' Disagree/neither agree nor disagree = 'strongly disagree', 'somewhat disagree' and 'neither agree nor disagree'; agree = 'somewhat agree' and 'strongly agree'. tResponses to the statement 'In my family, I often eat alone' were used to identify eating alone groups: 'does not often eat alone' group = 'strongly disagree', 'somewhat disagree' and 'neither disagree nor agree' responses; 'often eat alone' group = 'strongly agree' and 'somewhat agree' responses.

$\ddagger n$ and \% of total with non-missing data.

$\S P$ value for $\chi^{2}$ test; $P<0.007$ is significant after adjusting for multiple comparisons (Bonferroni correction).

Table 5 Unadjusted between-group differences in median food intake daily frequency ${ }^{\star}$ among US adolescents (aged 12-17 years) who completed Family Life, Activity, Sun, Health, and Eating (FLASHE) Study surveys, April-October 2014

\begin{tabular}{|c|c|c|c|c|c|c|c|}
\hline & \multirow[b]{3}{*}{$n$} & \multicolumn{5}{|c|}{ Eating alone group $\dagger$} & \multirow[b]{3}{*}{$P$ value } \\
\hline & & \multicolumn{2}{|c|}{ Often eat alone } & \multirow[b]{2}{*}{$n$} & \multicolumn{2}{|c|}{ Does not often eat alone } & \\
\hline & & Median $\ddagger$ & IQR‡ & & Median $\ddagger$ & IQR & \\
\hline Junk food & 321 & 1.58 & $1 \cdot 16-2 \cdot 29$ & 1243 & 1.58 & $1 \cdot 16-2 \cdot 29$ & 0.027 \\
\hline Convenience/fast food & 320 & 1.45 & $0.87-2.00$ & 1251 & 1.29 & $0.87-1.74$ & 0.0009 \\
\hline Sugar-sweetened beverages & 318 & 1.00 & $0.58-2.00$ & 1238 & 0.87 & $0.58-1.58$ & 0.013 \\
\hline $\begin{array}{l}\text { Junk food and sugar-sweetened beverages } \\
\text { without frozen dessert and energy drinks }\end{array}$ & 309 & $2 \cdot 45$ & $1.58-4.00$ & 1220 & $2 \cdot 29$ & $1.52-3.29$ & 0.008 \\
\hline Sugary food & 326 & 1.29 & $0.87-2.00$ & 1259 & $1 \cdot 16$ & $0.58-1.71$ & 0.008 \\
\hline Fatty meat & 325 & 0.71 & $0.29-1.29$ & 1267 & 0.58 & $0.29-0.87$ & 0.0002 \\
\hline All detrimental foods & 294 & 4.58 & $3.32-6.87$ & 1155 & $4 \cdot 19$ & $3 \cdot 03-5 \cdot 61$ & 0.007 \\
\hline All beneficial foods & 310 & 4.44 & $2.90-6.58$ & 1207 & $5 \cdot 29$ & $3.58-7.16$ & $<0.0001$ \\
\hline Fruits and vegetables & 315 & 1.87 & $1.16-3.29$ & 1223 & $2 \cdot 29$ & $1.45-3.71$ & $<0.0001$ \\
\hline
\end{tabular}

IQR, interquartile range.

*Top-coded food frequency scale variables for daily intake.

†Responses to the statement 'In my family, I often eat alone' were used to identify eating alone groups: 'does not often eat alone' group = 'strongly disagree', 'somewhat disagree' and 'neither disagree nor agree' responses; 'often eat alone' group = 'strongly agree' and 'somewhat agree' responses.

¥Median and IQR (= quartile 1-quartile 3) for those with non-missing data.

$\S P$ value for Wilcoxon signed-rank test; $P<0.005$ is significant after adjusting for multiple comparisons (Bonferroni correction).

children usually become more independent and spend more time away from their parents. With these issues in mind, the current study focused on the eating behaviours, weight status and adolescents' perceptions of supportive food-related parenting practices for those who often eat alone compared with those who do not often eat alone.

The FLASHE Study collected information on adolescent and parent perceptions of food-related parenting 
Table 6 Logistic regression models for adolescents eating alone (weighted) among US adolescents (aged 12-17 years) who completed Family Life, Activity, Sun, Health, and Eating (FLASHE) Study surveys, April-October 2014

OR estimates for adolescents often eating alone* (FLASHE raking weights for Adolescent Diet Survey applied) (n 1370)

\begin{tabular}{|c|c|c|c|}
\hline & \\
\hline & Adjusted OR estimate & $95 \%$ Wald confidence limits & $P$ value \\
\hline \multicolumn{4}{|l|}{ Adolescent age group } \\
\hline $12-13$ years & 1.000 & Ref. & \\
\hline 14-17 years & $1 \cdot 279$ & $0.917,1.784$ & $0 \cdot 147$ \\
\hline \multicolumn{4}{|l|}{ Adolescent race/ethnicity } \\
\hline Non-Hispanic White alone & 1.000 & Ref. & \\
\hline Hispanic & $1 \cdot 139$ & $0.689,1.881$ & 0.612 \\
\hline Non-Hispanic White alone & 1.000 & Ref. & \\
\hline Non-Hispanic Black alone & 1.741 & $1 \cdot 163,2 \cdot 607$ & 0.007 \\
\hline Non-Hispanic White alone & 1.000 & Ref. & \\
\hline Other & 1.470 & $0.922,2.343$ & 0.105 \\
\hline \multicolumn{4}{|l|}{ Adolescent sex } \\
\hline Male & 1.000 & Ref. & \\
\hline Female & 1.083 & $0.808,1.453$ & 0.592 \\
\hline \multicolumn{4}{|l|}{ Adolescent weight group } \\
\hline Normal- or overweight & 1.000 & Ref. & \\
\hline Overweight/obese & 1.647 & $1 \cdot 201,2 \cdot 257$ & 0.002 \\
\hline \multicolumn{4}{|l|}{ Adolescent-reported FV available in home } \\
\hline Never/rarely/sometimes & 1.000 & Ref. & \\
\hline Often/always & 0.645 & $0.437,0.952$ & 0.027 \\
\hline \multicolumn{4}{|l|}{ Adolescent-reported sweets available in home } \\
\hline Never/rarely/sometimes & 1.000 & Ref. & \\
\hline Often/always & 1.384 & $1.001,1.912$ & 0.049 \\
\hline \multicolumn{4}{|l|}{$\begin{array}{l}\text { Adolescent-reported: Parents and I decide together how many FV } \\
\text { I have to eat }\end{array}$} \\
\hline Disagree/neither agree nor disagree & 1.000 & Ref. & \\
\hline Somewhat/strongly agree & 0.714 & $0.513,0.993$ & 0.045 \\
\hline \multicolumn{4}{|l|}{ Adolescent-reported: It's OK for parents to make rules about JF } \\
\hline Disagree/neither agree nor disagree & 1.000 & Ref. & \\
\hline Somewhat/strongly agree & 0.706 & $0.513,0.974$ & 0.034 \\
\hline $\begin{array}{l}\text { Adolescent JF and sugary drink daily intake frequency without } \\
\text { frozen desserts or energy drinks ( } 1 \text { daily intake frequency } \\
\text { increase) }\end{array}$ & 1.095 & $1.002,1.196$ & 0.044 \\
\hline $\begin{array}{l}\text { Adolescent FV daily intake frequency (1 daily intake frequency } \\
\text { increase) }\end{array}$ & 0.928 & $0.843,1.023$ & $0 \cdot 134$ \\
\hline \multicolumn{4}{|l|}{ Parent marital status } \\
\hline Married & 1.000 & Ref. & \\
\hline Divorced, widowed or separated & 1.408 & $0.906,2 \cdot 188$ & 0.128 \\
\hline Married & 1.000 & Ref. & \\
\hline Member of an unmarried couple & 1.004 & $0.471,2 \cdot 137$ & 0.992 \\
\hline Married & 1.000 & Ref. & \\
\hline Never married & 1.245 & $0.756,2.050$ & 0.389 \\
\hline
\end{tabular}

FV, fruits and vegetables; JF, junk food; ref., reference category.

*Somewhat/strongly agree that they often eat alone.

practices; however, only adolescent perceptions were examined in the current study, similar to previous studies ${ }^{(21-23)}$. Adolescents' perceptions of home physicaland socio-environmental factors affecting their dietary intake are relevant to their reported behaviours. Authors of a review on measurement of food parenting indicated that important qualitative differences existed between adolescent-reported and parent-reported food-related parenting practices ${ }^{(33)}$. Others have reported lack of congruence between parents and their adolescent children about communication and decision making around food $^{(34)}$, and lack of concordance among parents regarding parent-reported home food and physical activity environmental factors that influence adolescent eating patterns and physical activity ${ }^{(35)}$. In addition, social desirability bias may result in parents under-reporting their own negative perceptions/behaviours and over-reporting positive perceptions/behaviours ${ }^{(34)}$. Therefore, consideration of adolescent perceptions of the home food environment and parenting practices was of interest in the current study.

The frequency of eating alone has been assessed in different ways among children and adolescents in several studies. For example, US National Health and Nutrition Examination Survey data (2007-2010) showed that the frequency of meals the family ate together with a youth aged 6-19 years ranged from $4 \cdot 2$ to $6 \cdot 1$ meals per week ${ }^{(36)}$, indicating that a number of meals were eaten alone or away from family members per week. Middle-school students in another study reported spending about $19 \%$ of their time 
eating alone ${ }^{(37)}$. Results from another sample of middleschool students indicated that $5 \%$ ate dinner alone based on a cross-sectional, web-based survey regarding food intake for eating occasions throughout the previous day ${ }^{(38)}$. In our study, $21 \%$ of adolescents agreed that they often eat alone when asked about their agreement with one statement: 'In my family, I often eat alone'. Lack of consistent measures and limited assessment of the frequency of eating alone in previous studies constrain the ability to evaluate the relevance of eating alone to adolescent dietary quality. Additional study of methods to assess the frequency of eating alone are needed, possibly including non-survey measures such as observational coding and ecological momentary assessment, as suggested by others ${ }^{(33)}$.

Potential parental demographic and household characteristics that could explain why adolescents in the current study reported often eating alone were examined. These variables included household composition based on marital status and variables related to family socio-economic status such as parental employment, work hours, education and household income. However, only parental marital status was associated with adolescents eating alone in unadjusted analysis and was not significantly associated with adolescents eating alone after adjusting for other factors in the regression model. In contrast in another study, more middleschool students with a low school-level socio-economic status reported that they ate dinner alone than students with a higher school-level socio-economic status in a web-based survey $^{(38)}$. In the current study, the odds of adolescents agreeing that they often eat alone were significantly higher for non-Hispanic Black adolescents compared with nonHispanic White adolescents after adjusting for other factors in the regression model. These findings indicate that further study is needed to determine how household composition, socio-economic status and race/ethnicity might interact to explain the frequency of adolescents eating alone. The percentage of adolescents agreeing that they often eat alone and associations with race/ethnicity in the current study are of concern, given the observed relationship with less healthy eating behaviours and overweight and obesity.

Results from our study showed that the odds of often eating alone were higher for each additional one daily intake frequency of junk food/sugary drinks. Parental supervision is lacking during independent eating occasions; therefore adolescents have greater responsibility for preparing meals and selecting foods and beverages for snacks and meals. Interviews with low-income adolescents with primary responsibilities for cooking in the home indicated that food choices were attributed to their familiarity with a dish and/or ingredients, cooking skills, consultation with the primary household food preparer and the type of foods available in the home ${ }^{(39)}$. Our results indicate that the likelihood of often eating alone was associated with adolescents reporting a higher availability of sweets in the home and lower availability of FV in the home. Therefore, availability may explain, in part, the higher odds of eating alone for each additional one daily intake frequency of junk food/sugary drinks. Consistent with our findings, Loth et al. ${ }^{(17)}$ found that healthy food availability was positively associated with adolescent FV intake and negatively associated with snack and soda consumption. Parenting practices (fruit and vegetable access and availability) were stronger determinants of adolescent FV intake than family meals in another study ${ }^{(22)}$.

In the current study, overweight and obese adolescents were more likely to report eating alone than normal- or underweight adolescents. Similar results were reported among Japanese adolescents aged 12-13 years based on cross-sectional surveys showing that girls but not boys who reported eating dinner alone more often were more likely to be overweight ${ }^{(40)}$. Eating dinner alone was related to energy intake among young adolescents (mean age 12.3 years) who completed a web-based survey to report intake on the previous day ${ }^{(38)}$. Less energy was consumed during the dinner meal when eating with family members than when eating alone. Eating with others $v$. eating alone may present different social cues which could be related to intake and therefore weight status. Among adults who logged everyday snacking behaviour for two weeks, those with a higher BMI were more likely to consume higher-energy snacks when they were alone than those with a lower BMI ${ }^{(41)}$, indicating that weight status was related to responsiveness to social cues such as seeing others eat or eating alone. Limited research among adolescents is available regarding the relationship between weight status and eating alone; however, the positive relationship found in the few published studies in this field indicates a need for further studies to determine how eating alone affects energy intake and weight status.

Adjusted odds of adolescents often eating alone in the current study were lower for those who agreed that they made decisions with parents about how many FV they have to eat and for adolescents who agreed that it's OK for parents to make rules about how much junk food/sugary drinks they can have. These findings support the idea that adolescents who often eat alone have a sense of independence regarding their food and beverage intake and are taking responsibility for their own food choices. Preparation for making healthy choices during independent eating occasions should be based on the use of autonomy-supportive parenting practices ${ }^{(18)}$. These include encouragement of healthy eating, education/reasoning and involving the adolescent in meal planning, grocery shopping and meal preparation $^{(16)}$. Autonomy promotion could therefore produce the intrinsic motivation and confidence for adolescents to follow parental rules during independent eating occasions.

A limitation of our study was that although the study sample was a nationwide sample, it was not nationally representative, limiting our ability to generalize findings to the US adolescent population. Intake frequency of foods and beverages, height and weight were self-reported and therefore subject to recall and social desirability biases. In addition, the study design was cross-sectional and thus it is impossible to make inferences about causation. 


\section{Conclusions}

Overweight or obese adolescents $v$. normal- or underweight adolescents and non-Hispanic Black $v$. nonHispanic White adolescents were more likely to report often eating alone. The odds of often eating alone were higher for each one additional daily intake frequency of junk food/sugary drinks and the likelihood of often eating alone was associated with adolescents reporting a lower availability of FV and a higher availability of sweets in the home. The odds of adolescents often eating alone were lower for those who agreed with two parenting practice items based on setting expectations for intake of FV and accepting parents' rules about these expectations. Adolescence is considered a foundational life stage where individual patterns for long-term health behaviours are established that last into and throughout adulthood $^{(42)}$. Eating patterns in adolescence are generally seen as remaining stable into adulthood ${ }^{(43,44)}$. Researchers have shown that adolescents eating together with their family acts as a protective factor against overweight and obesity, as well as unhealthy eating patterns. American lifestyle changes have resulted in fewer family meals ${ }^{(2,3)}$, which may indicate that adolescents eat alone more often. Therefore, limited opportunities may exist for parents to encourage and model healthy food choices. The results of the current study indicate that public health professionals could promote autonomy-supportive parenting and improved availability and accessibility of healthy foods to foster healthy eating among adolescents. Additional research is needed to identify frequency of eating alone among adolescents based on a more precise measure than was used in the current study, along with reasons for eating alone. Further studies on the relationship of frequency of eating alone among adolescents with energy, food group and nutrient intakes, and weight status could also improve understanding of potentially effective intervention strategies for parents and adolescents to improve intake when adolescents eat alone.

\section{Acknowledgements}

Financial support: This project was funded through money appropriated by Congress through the Hatch Act to the Agricultural Experiment Stations of land grant universities for multistate research projects. These funding bodies had no role in the design of the study; collection, analysis and interpretation of data; or in writing the manuscript. This research was supported by the National Institutes of Health's National Center for Advancing Translational Sciences (grant number UL1TR002494). The content is solely the responsibility of the authors and does not necessarily represent the official views of the National Institutes of Health's National Center for Advancing
Translational Sciences. Conflict of interest: The authors declare that they have no competing interests. Authorship: M.R., C.D., A.K.A., J.B., M.K., C.G., B.J., R.R., G.T. and S.S.W. conceptualized the research question and data analysis approach. C.D. analysed the data regarding relationships between variables of interest. M.R., C.D., A.K.A., J.B., M.K., C.G., B.J., R.R., G.T. and S.S.W. interpreted the findings and were major contributors in writing the manuscript. All authors read and approved the final manuscript. Ethics of buman subject participation: This study was conducted according to the guidelines laid down in the Declaration of Helsinki and all procedures involving human subjects were approved by the US Government's Office of Management and Budget, National Cancer Institute Special Studies Institutional Review Board and Westat's Institutional Review Board. FLASHE data collection materials and procedures were reviewed and approved by the US Government's Office of Management and Budget (OMB clearance date/number: 13 December 2013/0925-0686), NCI's Special Studies Institutional Review Board (SSIRB clearance date/iRIS number: 30 May 2013/327123) and Westat's Institutional Review Board (IRB clearance date/number: 14 March 2013/6053.01.01). Parents and adolescents were contacted by an Internet consumer panel (Ipsos Consumer Opinion Poll) by email and invited to enrol via a website where they were asked to complete consent and assent forms prior to participation. The University of Minnesota's Institutional Review Board determined that this secondary analysis of existing anonymous data was exempt from review.

\section{References}

1. Pew Research Center (2015) Parenting in America: Outlook, worries, aspirations are strongly linked to financial situation. http://www.pewresearch.org/wp-content/uploads/sites/3/20 15/12/2015-12-17_parenting-in-america_FINAL.pdf (accessed November 2018).

2. Walton D, Kleinman KP, Rifas-Shiman SL et al. (2016) Secular trends in family dinner frequency among adolescents. BMC Res Notes $\mathbf{9}, 35$.

3. Neumark-Stzainer D, Wall M, Fulkerson JA et al. (2013) Changes in the frequency of family meals from 1999 to 2010 in the homes of adolescents: trends by sociodemographic characteristics. J Adolesc Health 52, 201-206.

4. Fulkerson JA, Larson N, Horning M et al. (2014) A review of associations between family or shared meal frequency and dietary and weight status outcomes across the lifespan. J Nutr Educ Behav 46, 2-19.

5. Martin-Biggers J, Spaccarotella K, Berhaupt-Glickstein A et al. (2014) Come and get it! A discussion of family mealtime literature and factors affecting obesity risk. Adv Nutr $\mathbf{5}$, 235-247.

6. Horning ML, Schow R, Friend SE et al. (2017) Family dinner frequency interacts with dinnertime context in associations with child and parent BMI outcomes. J Fam Psychol 31, 945-951.

7. Berge JM, Jin SW, Hannan P et al. (2013) Structural and interpersonal characteristics of family meals: associations with adolescent body mass index and dietary patterns. J Acad Nutr Diet 113, 816-822. 
8. Hammons AJ \& Fiese BH (2011) Is frequency of shared family meals related to the nutritional health of children and adolescents? Pediatrics 127, e1565-e1574.

9. Berge JM, Wall M, Hsueh TF et al. (2015) The protective role of family meals for youth obesity: 10-year longitudinal associations. J Pediatr 166, 296-301.

10. Goldfield GS, Murray MA, Buchholz A et al. (2011) Family meals and body mass index among adolescents: effects of gender. Appl Physiol Nutr Metab 36, 539-546.

11. Neumark-Sztainer D, Larson NI, Fulkerson JA et al. (2010) Family meals and adolescents: what have we learned from Project EAT (Eating Among Teens)? Public Health Nutr 13, 1113-1121.

12. Rollins BY, Belue RZ \& Francis LA (2010) The beneficial effect of family meals on obesity differs by race, sex, and household education: the National Survey of Children's Health, 2003-2004. J Am Diet Assoc 110, 1335-1339.

13. Reicks M, Banna J, Cluskey $M$ et al. (2015) Influence of parenting practices on eating behaviors of early adolescents during independent eating occasions: implications for obesity prevention. Nutrients $\mathbf{7}, 8783-8801$.

14. Cruwys T, Bevelander KE \& Hermans RCJ (2015) Social modeling of eating: a review of when and why social influence affects food intake and choice. Appetite 86, 3-18.

15. Birch LL, Fisher JO \& Davison KK (2003) Learning to overeat: maternal use of restrictive feeding practices promotes girls' eating in the absence of hunger. Am J Clin Nutr 78, 215-220.

16. Vaughn AE, Ward DS, Fisher JO et al. (2016) Fundamental constructs in food parenting practices: a content map to guide future research. Nutr Rev 74, 98-117.

17. Loth KA, MacLehose RF, Larson N et al. (2016) Food availability, modeling and restriction: how are these different aspects of the family eating environment related to adolescent dietary intake? Appetite 96, 80-86.

18. Ryan R \& Deci E (2000) Self-determination theory and the facilitation of intrinsic motivation. Am Psychol 55, 68-78.

19. Grolnick WS (2003) The Psychology of Parental Control: How Well-Meant Parenting Backfires. Mahwah, NJ: Erlbaum.

20. Dwyer LA, Bolger N, Laurenceau J-P et al. (2017) Autonomous motivation and fruit/vegetable intake in parentadolescent dyads. Am J Prev Med 52, 863-871.

21. Girelli L, Hagger M, Mallia L et al. (2016) From perceived autonomy support to intentional behaviour: testing an integrated model in three healthy-eating behaviours. Appetite 96, 280-292.

22. Watts AW, Loth K, Berge JM et al. (2017) No time for family meals? Parenting practices associated with adolescent fruit and vegetable intake when family meals are not an option. $J$ Acad Nutr Diet 117, 707-714.

23. Gevers DWM, van Assema P, Sleddens EFC et al. (2015) Associations between general parenting, restrictive snacking rules, and adolescent's snack intake. The role of fathers and mothers and interparental congruence. Appetite 87, 184-191.

24. US Department of Health and Human Services, National Cancer Institute (2017) 2014 Family Life, Activity, Sun, Health and Eating (FLASHE) Survey Data. FLASHE Public Use Data Files and Supporting Documentation. http://can cercontrol.cancer.gov/brp/hbrb/flashe.html (accessed January 2018).

25. Nebeling LC, Hennessy E, Oh AY et al. (2017) The FLASHE Study: survey development, dyadic perspectives, and participant characteristics. Am J Prev Med 52, 839-848.

26. Oh AY, Davis T, Dwyer LA et al. (2017) Recruitment, enrollment, and response of parent-adolescent dyads in the FLASHE Study. Am J Prev Med 52, 849-855.

27. US Department of Health and Human Services, National Cancer Institute (NCI) (2017) 2014 Family Life, Activity, Sun,
Health and Eating (FLASHE) Survey Data. Guide for Data Users: Version 2, Updated October 2017. https://cancer control.cancer.gov/brp/hbrb/docs/FLASHE-Data-Users-Guide. pdf (accessed January 2018).

28. Centers for Disease Control and Prevention, Division of Nutrition, Physical Activity, and Obesity (2016) Nutrition I Growth Chart Training. http://www.cdc.gov/nccdphp/ dnpao/growthcharts/resources/sas.htm (accessed January 2018).

29. Birch LL, Fisher JO, Grimm-Thomas K et al. (2001) Confirmatory factor analysis of the Child Feeding Questionnaire: a measure of parental attitudes, beliefs, and practices about child feeding and obesity proneness. Appetite 36, 201-210.

30. Musher-Eizenman D \& Holub S (2007) Comprehensive feeding practices questionnaire: validation of a new measure of parental feeding practices. J Pediatr Psychol 32, 960-972.

31. Wardle J, Sanderson S, Guthrie CA et al. (2002) Parental feeding style and the inter-generational transmission of obesity risk. Obes Res 10, 453-462.

32. Darling N, Cumsille P \& Martinez ML (2008) Individual differences in adolescents' beliefs about the legitimacy of parental authority and their own obligation to obey: a longitudinal investigation. Child Dev 79, 1103-1118.

33. Musher-Eizenman DR \& Kiefner A (2013) Food parenting: a selective review of current measurement and an empirical examination to inform future measurement. Child Obes $\mathbf{9}$, Suppl., S32-S39.

34. de Bourdeaudhuij I \& van Oost P (2000) Personal and family determinants of dietary behavior in adolescents and their parents. Psychol Health 15, 751-770.

35. Berge JM, MacLehose RF, Meyer C et al. (2016) He said, she said: examining parental concordance on home environment factors and adolescent health behaviors and weight status. I Acad Nutr Diet 116, 46-60.

36. Masters MA, Krogstrand KLS, Eskridge KM et al. (2014) Race/ethnicity and income in relation to the home food environment in US youth aged 6 to 19 years. $J$ Acad Nutr Diet 114, 1533-1543.

37. Miller WC, Hering M, Cothran C et al. (2012) After-school physical activity and eating behaviors of middle school students in relation to adult supervision. J Nutr Educ Behav 44, 326-334.

38. Woodruff SJ, Campbell K, Campbell T et al. (2014) The associations of meals and snacks on family meals among a sample of grade 7 students from Southwestern Ontario. Appetite 82, 61-66.

39. Leak TM, Aasand TA, Vickers Z et al. (2018) The role of adolescents from a low socioeconomic background in household food preparation: a qualitative study. Health Promot Pract. Published online: 1 May 2018. doi: 10.1177/ 1524839918776647.

40. Shirasawa T, Ochiai H, Yoshimoto T et al. (2018) Effects of eating dinner alone on overweight in Japanese adolescents: a cross-sectional survey. BMC Pediatr 18, 36.

41. Schuz B, Revell S, Hills AP et al. (2017) Higher BMI is associated with stronger effects of social cues on snacking behavior. Appetite 114, 1-5.

42. Sawyer SM, Afifi RA, Bearinger LH et al. (2012) Adolescence: a foundation for future health. Lancet 379, 1630-1640.

43. Cutler GJ, Flood A, Hannan P et al. (2009) Major patterns of dietary intake in adolescents and their stability over time. J Nutr 139, 323-328.

44. Lake AA, Mathers JC, Rugg-Gunn AJ et al. (2006) Longitudinal changes in food habits between adolescence (11-12 years) and adulthood (32-33 years): the ASH30 study. J Public Health (Oxf) 28, 10-16. 